\title{
Integração inovadora entre empresas incubadas e universidades para geração contínua de vantagens competitivas em ambientes dinâmicos
}

\author{
Rogerio Tadeu de Oliveira Lacerda Doutor em Engenharia da Produção. Universidade Federal de Santa Catarina (UFSC) Brasil - rogerlacerda@gmail.com \\ Professor do PPGA/UFSC - Bolsista CNPQ de Produtividade em Desenvolvimento Tecnológico e Extensão Inovadora DT-II \\ Brianna Luiza Klein Graduanda em Administração. Universidade Federal de Santa Catarina (UFSC) Brasil - briannaluizaklein@gmail.com \\ Julia Figueiredo Fulco Graduanda em Design. Universidade Federal de Santa Catarina (UFSC) Brasil - juf.fulco@gmail.com. \\ Gabriel Santos Associação Catarinense de Empresas de Tecnologia (ACATE) Brasil - gabriel@acate.com.br \\ Kamilla Bittarello Associação Catarinense de Empresas de Tecnologia (ACATE) Brasil - midi@acate.com.br
}

\section{RESUMO}

Esse artigo apresenta uma abordagem de integração entre startups e universidade, tendo como objetivos: (i) difundir práticas gerenciais inovadoras em empresas ligadas à incubadoras de empresas, (ii) estreitar a relação entre teoria e prática no ensino da Administração sobretudo em ambiente dinâmicos, (iii) criar um ambiente propício ao desenvolvimento das competências dos alunos do curso de Administração em um enfoque de aprendizagem pela ação, ao mesmo tempo que os empresários das empresas incubadas possam refletir sobre seus processos de gestão. Tal intento é alcançado por meio de uma abordagem construtivista de aprendizagem ativa, com participação ativa dos alunos de graduação de um curso de administração, sob supervisão de um professorfacilitador e dos empresários das startups. Esse artigo apresenta resultados de casos exploratórios que visam entender problemas gerenciais de empresas incubadas na incubadora MIDI Tecnológico e propõe modelos de decisão para os empresários a partir de seus valores e preferências. Essa pesquisa apresenta inovação no aspecto gerencial, onde é apresentado o uso da abordagem Lean Startup junto ao apoio à decisão construtivista, para avaliar e criar alternativas de ações no tocante ao desenvolvimento de produto e mercado. E em adição, esse trabalho também apresenta uma abordagem de integração inovadora entre empresas incubadas e universidades, onde a primeira pode se valer de conhecimento gerenciais presentes nos cursos de administração para melhorar seu desempenho, bem como os acadêmicos podem se valer da aprendizagem vivencial para aplicar conhecimentos que precisarão ser melhor explorados durante sua vida acadêmica e profissional.

Palavras-chave: Inovação. Construtivismo. Incubação de empresas. Decisão. Educação.

\section{Innovative integration between incubated startups and universities to achieve continuous competitive advantages in dynamic enviroments}

\begin{abstract}
This article intents to show an approach of integration between startups and the university through the generation and diffusion of scientific and applied knowledge. The goals of this paper are to: (i) disseminate innovative management practices in companies that belong to business incubators; (ii) narrow the relation between theory and practice in business management education, especially in dynamic environments; (iii) create a favorable environment for students of the Business school to develop the necessary skills of management through the active learning, while entrepreneurs of incubated startups can think over their management processes. This purpose is achieved through a constructivist approach to active learning with the dynamic participation of undergraduate students of the Business course, under the supervision of a professor-facilitator and the engagement of managers of business start-ups. The article presents the results of exploratory cases that aimed to understand management problems of incubated startups in the Technological MIDI incubator. Then the article proposes a decision model to assist entrepreneurs, and relying on their values and preferences. The research introduces innovation in the management view as it presents the use of the Lean Startup approach supporting a constructivist decision making model to evaluate and plan alternative actions. In addition, it also presents an innovative integration approach between incubated companies and universities, in which the startup can acquire the knowledge of business strategies present in the business school to improve their performance and students can take advantage of active and practical learning gaining knowledge applicable in their academic and professional life.
\end{abstract}

Keywords: Innovation. Constructivism. Business incubation. Decision. Education. 


\section{INTRODUÇÃO}

O desafio que a sociedade moderna impõe às organizações, se replica nas relações de aprendizagem que ocorrem nos graduandos em processo de desenvolvimento profissional, intelectual e acadêmico no meio universitário.

As práticas pedagógicas tradicionais enfatizam uma forma mecanicista à solução de problemas bemestruturados, utilizando-se de abordagens baseadas em uma coleção de "boas práticas" que culminam em uma solução única, considerada como certa (WYNN-WILLIAMS; WHITING; ADLER, 2008).

Todavia, tais abordagens mecanicistas, falham em trazer aos alunos a complexidade e riqueza da vida organizacional, tal como ela é na realidade. Em decorrência disso, sérias consequências são impelidas aos alunos, uma vez que esses desenvolvem visões distorcidas e limitadas sobre suas carreiras e o cotidiano dentro de uma organização (WYNN-WILLIAMS; WHITING; ADLER, 2008).

Nesse contexto desafiador, emerge a importância da reflexão sobre os métodos de ensino e aprendizagem aplicados nos sistemas educacionais de ensino superior, tanto os brasileiros, quanto os mundiais. Assim, este trabalho se assenta em uma proposta metodológica, onde a aprendizagem é baseada em função de problemas reais e estratégicos de duas startups.

Os dois casos resultantes da aplicação dessa abordagem são apresentados com vista aos alunos proporem modelos de gestão que auxiliem os empreendedores da incubadora MIDI Tecnológico. De forma propositiva, os participantes dos projetos selecionaram uma metodologia multicritério de apoio à decisão construtivista e a integraram com o método Lean Startup - LS, (RIES, 2011). Como resultado, apresentam-se dois modelos de apoio à decisão com critérios, indicadores e escalas para estruturação e priorização de ações no tocante ao desenvolvimento de produto e mercado.

Dessa forma, esse artigo apresenta uma abordagem de integração entre startups e universidade gerando ganhos mútuos.

O objetivo desse artigo é ilustrar os resultados de uma metodologia que se propõe: (i) difundir práticas gerenciais inovadoras em startups ligadas à incubadoras de empresas, (ii) estreitar a relação teoria e prática no ensino da Administração, sobretudo em ambientes dinâmicos, (iii) criar um ambiente propício ao desenvolvimento das competências dos alunos em um enfoque de aprendizagem pela ação, ao mesmo tempo que os empresários das empresas incubadas possam refletir sobre seus processos de gestão.

O artigo é disposto nas seguintes seções: referencial teórico sobre gestão de empresas de base tecnológica e aprendizagem ativa; seção de métodos adotados por essa pesquisa; apresentação da síntese dos dois casos apresentados; considerações finais e referências bibliográficas utilizadas.

\section{REFERENCIAL TEÓRICO}

A seguir, é exposto referencial teórico dos temas dessa pesquisa: gestão de empresas de base tecnológica e aprendizagem ativa.

\subsection{Gestão de Empresas de Base Tecnológica - EBTs}

As dimensões de inovação, flexibilidade e agilidade, vêm transformando as diversas formas de competição empresarial. Estas se intensificam em ambiente dinâmicos, como no caso de empresas que têm na tecnologia o seu core business, aqui denominadas como Empresas de Base Tecnológica - EBTs.

Essas EBTs têm algumas características distintas da tradicional indústria, como: o dinamismo de mercado, ciclos de vida de produto cada vez mais curtos, mudanças frequentes dos critérios de competição entre empresas e intangibilidade dos recursos internos.

Assim, tais dimensões provocam a reflexão, adequação e evolução dos métodos administrativos.

A gestão de projetos, previamente voltada para a ordenação de atividades de modo a alcançar o prazo e custo planejado evoluiu de forma a planejar, executar e controlar o projeto, baseando-se em iterações sucessivas que 
permitem continuamente dissipar as incertezas e gerenciar melhor os riscos nos projetos inovadores (LACERDA; ENSSLIN; ENSSLIN, 2011).

Já a gestão de processos, antes focada na padronização, surge como um instrumento para alinhar as diferentes áreas organizacionais da empresa de modo a atender os objetivos singulares de cada organização (TRKMAN, 2010). Para tanto, há a necessidade de flexibilidade nos processos e empoderamento das equipes, que nas EBTs são multidisciplinares.

Os instrumentos de avaliação de desempenho evoluíram de modo a construir conhecimento nos gestores sobre os fatores críticos de sucesso para suas EBTs, reconhecendo a singularidade de seus recursos e produtos, bem como, criando um processo de inovação (HUDSON; SMART; BOURNE, 2001).

A gestão de pessoas também evoluiu de forma a criar organizações mais flexíveis, com menos níveis hierárquicos, sistema de cargos de forma a desafiar as competências de cada colaborador, além de um sistema de recompensas que possa motivar e reter talentos, cada vez mais ávidos por desafios e realização profissional e pessoal. Em suma, a gestão de pessoas nas EBTs opera agora com o paradigma de criar uma cultura organizacional voltada à inovação e empreendedorismo.

Tais exemplos de evolução dos processos administrativos são representados por novos modelos gestão, como lean (HASIN; BURCHER, 2006; ACHANGA, 2006; PETTERSEN, 2009) e ágil (HALLGREN; OLHAGER, 2009; QUMER; HENDERSON-SELLERS, 2008; DINGSØYR et al, 2012), que foram amplamente discutidos e implementados no setor industrial, mas que ainda estão sendo adaptados para o contexto das EBTs.

É nesse contexto que emerge a necessidade de projetos de pesquisa e extensão a respeito de como as EBTs podem tirar proveito desses novos conceitos e tendências para seu sucesso empresarial, no contexto de um programa universitário que se centra em uma abordagem de aprendizagem ativa detalhada da próxima seção.

\subsection{Aprendizagem ativa}

Aprendizagem ativa é um termo genérico para técnicas pedagógicas que requerem do educador privilegiar a participação dos alunos, a partir de sua própria visão sobre um dado assunto (MACVAUGH; NORTON, 2012). Seu foco então, é resolver um problema a partir da construção de conhecimento dos participantes sobre o mesmo (PEDLER, 2011).

Tal abordagem se caracteriza pela adoção de grupos pequenos de participantes que se encontram durante um tempo regular, para lidar com problemas reais e executar investigação e ações, refletindo e aprendendo com a sua própria experiência e a de outros (EDMONSTONE, 2003; PEDLER, 2011).

Assim, a questão de quem assume a responsabilidade para protagonizar a aula merece muito mais atenção do que vem sido dado no passado (WYNN-WILLIAMS; WHITING; ADLER, 2008; POWNER; ALLENDOERFER, 2008).

A abordagem de aprendizagem ativa instiga os alunos a construir o seu próprio conhecimento por meio de discussões, encenações de papéis, simulação, aprendizagem baseada em problemas, entre outros métodos. Desse modo, aprendizagem ativa é frequentemente contrastada com os tradicionais formatos de ensino, baseados em apresentações ou exposições teóricas, que envolvem os alunos de forma passiva, não exigindo uma descoberta por parte dos mesmos, mas apenas assimilação e entendimento de conceitos (POWNER; ALLENDOERFER, 2008).

Assim, para definir aprendizagem ativa é importante destacar a suas diferenças dos métodos tradicionais de educação superior, principalmente das abordagens didáticas que se valem de memorização e entendimento de sistemas estáticos, que estimulam apenas a concentração dos alunos em indicadores superficiais, ao invés de princípios fundamentais da aprendizagem (MCCARTHY; ANDERSON 2000).

Essa característica é bem relevante para futuros gestores, pois a aprendizagem organizacional não se trata somente da aquisição de conhecimento impessoal, fruto de uma coleta de dados sobre um problema. Para que as decisões gerenciais sejam efetivas é necessário atitude e habilidade para selecionar quais dados serão indispensáveis para se tornarem informação necessária, de modo a melhorar uma situação (PEDLER, 2011).

Logo, é particularmente valioso desenvolver estruturas e dinâmicas que valorizem um sistema organizacional de aprendizagem e que os tomadores de decisão aceitem que eles não vão ter sucesso simplesmente replicando respostas encontradas em outros ambientes ou procurando a "solução ótima". Dessa forma, se torna evidente o reconhecimento da singularidade dentro de um processo de aprendizagem ativa e de inovação (PEDLER, 2011). 
Esse tipo de aprendizagem é importante em todos os campos de conhecimento, mas se torna crucial nas áreas de humanas e ciências sociais (MCCARTHY; ANDERSON, 2000), dado que potencializa o desenvolvimento do pensamento crítico e de habilidades reflexivas para suportar futuras decisões no meio organizacional (MACVAUGH; NORTON, 2012).

As etapas para aprendizagem ativa podem variar de um método para outro, mas possuem algumas delas em comum, como: problematização, investigação, resolução do problema e reflexão crítica (MACVAUGH; NORTON, 2012; PEDLER, 2011; LORD, 1997).

A problematização requer que o aluno considere o que ele realmente sabe sobre determinado tema (MACVAUGH; NORTON, 2012). Esse processo de reconhecimento da própria limitação de conhecimento se desenvolve muito mais por perguntas de qualidade, que simplesmente a busca por respostas imediatas ou que deram certo em outros contextos (PEDLER, 2011; LORD, 1997).

A investigação do problema requer que a aprendizagem considere os elementos sem um conteúdo programático pré-definido, mas onde o aluno desenvolve seu próprio esquema cognitivo, de forma a conseguir traçar relações interdisciplinares acerca da questão e localizar como cada área de conhecimento pode contribuir para sua resolução (MACVAUGH; NORTON, 2012; LORD, 1997).

Assim, a resolução de problemas fornece ao aluno uma oportunidade para agir e se valer da criatividade de forma a colocar em prática o seu aprendizado. Isto é, provavelmente, o mais importante elemento para a inovação, dado que a mudança organizacional depende do comportamento e não da simples noção de identificação de um problema ou conceitos teóricos (MACVAUGH; NORTON, 2012).

Por fim, a reflexão crítica traz ao aluno a avaliação do processo usado para resolver o problema (MACVAUGH; NORTON, 2012). A avaliação da absorção do conteúdo, nesse caso, se dá pela aplicabilidade do conhecimento adquirido e também pela a capacidade argumentativa dos alunos sobre os caminhos que eles estão trilhando, ou seja, tanto o know-how como o know-why.

O papel do professor e do docente merece destaque nesse modelo de ensino e aprendizagem. O papel do docente, neste contexto, não cabe à simples exposição de conteúdo, mas sim, à busca por perguntas norteadoras. Essa mudança de papel, incentiva os alunos a se tornarem protagonistas da solução e do contexto de aprendizagem (PEDLER, 2011).

Nessa linha de pensar, esse projeto tem algumas premissas de trabalho que são utilizadas por essa pesquisa: (i) multidisciplinaridade; (ii) aprendizagem vivencial (construtivismo); (iii) colaboração; (iv) trabalhar com casos reais; (v) professor como facilitador; (vi) fomento à pesquisa; (vii) fomento à criatividade e inovação; (viii) integração da Universidade com Sociedade.

Na próxima seção, tais premissas de trabalho do projeto são descritas como foram operacionalizadas para efeitos desse artigo.

\section{METODOLOGIA}

A seguir serão expostos o enquadramento e os métodos aplicados por essa pesquisa.

\subsection{Enquadramento metodológico}

Essa seção visa explicitar os elementos da metodologia científica utilizada por essa pesquisa para atingir os objetivos propostos.

A presente pesquisa se caracteriza como exploratória por se propor a aperfeiçoar teorias e ideias no contexto da tomada de decisão, por meio da familiarização do pesquisador com um problema em específico, da explicitação das características do problema e pela elaboração de recomendações em como esse problema possa ser endereçado.

Em referência à natureza de pesquisa, esse trabalho científico visa utilizar o estudo de caso, por este se aprofundar no estudo do objeto de pesquisa de forma a ampliar e detalhar o conhecimento necessário para atingir os objetivos da mesma (GIL, 1991).

Segundo Yin (2013), o estudo de caso preserva as características significativas dos eventos da vida real, se constituindo em um elemento para a consolidação da natureza prática da presente pesquisa. 
Quanto à coleta de dados, esta pesquisa se vale de fontes primárias para identificar os fatores considerados necessários e suficientes para avaliação de um contexto. A abordagem de pesquisa desse projeto, caracteriza-se como qualitativa, pois a estruturação do modelo para apoiar as decisões, segue os valores e preferências dos decisores dada uma determinada circunstância.

\subsection{Abordagem construtivista de apoio à decisão}

Antes de expor os procedimentos utilizados por essa pesquisa, faz-se necessária a exposição das convicções e problemáticas do processo de apoio à decisão, na qual se baseia o presente trabalho científico.

Este artigo está fundamentado em três convicções de natureza metodológica: convicção da interpenetração de elementos objetivos e subjetivos e da sua inseparabilidade; convicção da aprendizagem pela participação; e convicção do construtivismo (BANA E COSTA, 1995).

Dessa forma, o diálogo, a discussão, os gráficos, os desenhos e as representações pictóricas serão utilizadas (ENSSLIN; MONTIBELLER NETO; NORONHA, 2001) para conduzir um processo decisório, ressaltando a sinergia entre o facilitador e os atores do contexto, o que colabora para a ampliação do conhecimento em relação ao problema estudado a partir de seus valores e preferências (ROY, 1993).

Trabalhando sob a convicção construtivista, os métodos de trabalho permitem levar em conta os aspectos subjetivos de um grupo de decisores, frequentemente permeado com conflitos de interesse provindos de pontos de vistas distintos sobre um mesmo problema.

No construtivismo são desenvolvidas formas de expor as preferências dos decisores, onde os pontos conflitantes são analisados e, dessas diferenças de visões, há uma evolução do conhecimento sobre o contexto e o problema, permitindo advir novas formas de entender a situação e propor aperfeiçoamentos.

\subsection{Procedimentos técnicos}

Em função de seus objetivos e outros fatores de seu enquadramento metodológico, uma pesquisa científica pode adotar um ou mais procedimentos técnicos, desde que a abordagem selecionada para a pesquisa tenha coerência com seus propósitos (TRIVIÑOS, 1987).

A presente pesquisa se baseou nas etapas definidas por Marquardt (2005), referidas na Figura 1 e explicitadas no Apêndice $A$.

Figura 1 - Método de Aprendizagem em Ação

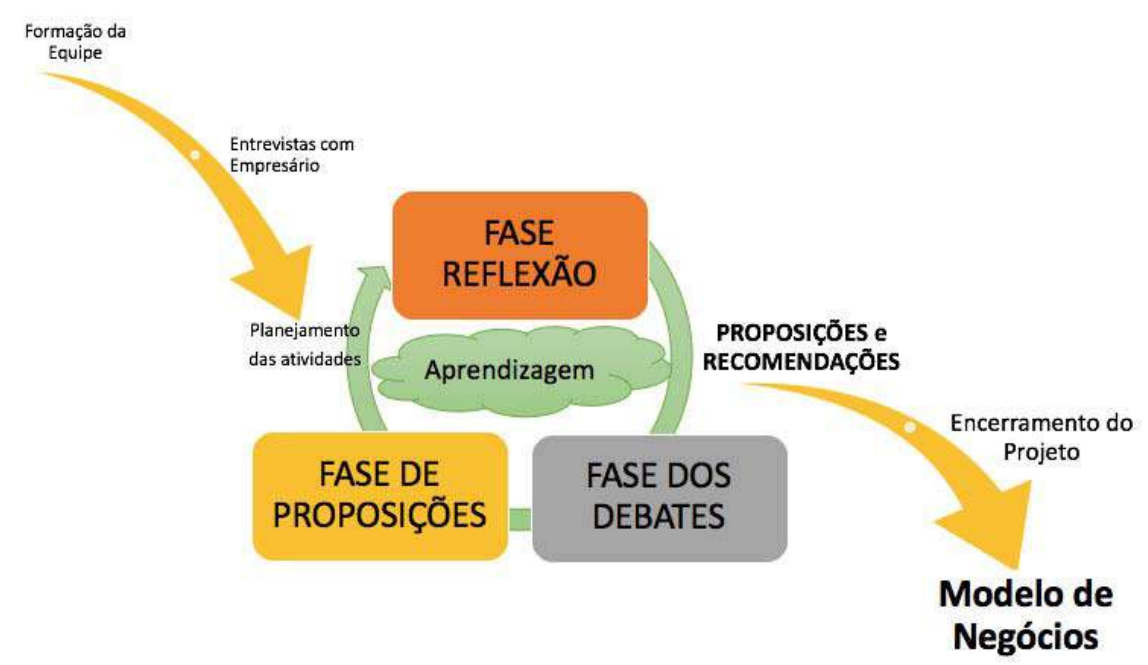

Fonte: Adaptado de Maquardt (2005). 
Na fase de formação da equipe de trabalho ocorre a prospecção de empresários (ator externo) em compartilhar um problema organizacional e seleção de alunos que farão parte do ciclo do projeto.

$\mathrm{Na}$ fase do contato com o problema, o ator externo realiza uma apresentação resumida sobre seu contexto e problema e os alunos realizam perguntas abertas ao ator externo. O professor-facilitador instiga aos alunos sobre quais disciplinas do currículo ou áreas de conhecimento em Administração seriam úteis para ajudar a estruturar o referido problema.

O planejamento das atividades se dá quando os alunos são incentivados a se organizarem em grupos de acordo com sua afinidade e interesse para cada área de conhecimento selecionada. Os grupos discutem os próximos passos, dentre eles:

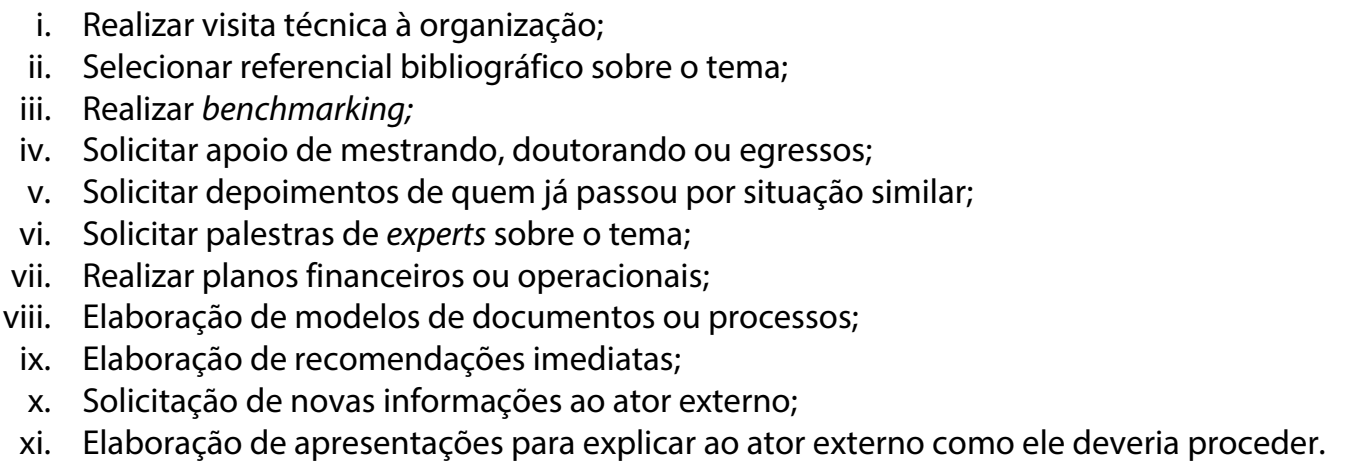

A seguir, o professor-facilitador promove reflexões nos alunos sobre o que eles aprenderam em cada encontro, onde se documenta em um mapa mental (mapa cognitivo), como reflexões teórica e práticas, riscos, pendências por falta de tempo, perguntas sem respostas, e polarizações de opiniões entre alunos.

Na fase seguinte, o professor-facilitador orienta os alunos na busca do conhecimento necessário para elaborar as recomendações, onde encontros semanais são realizados para que os alunos exponham aos demais suas dúvidas e questionamentos. Os alunos são incentivados a procurarem materiais relacionados, como notícias, vídeos, casos similares, artigos de revistas empresariais, exposição de experiências pessoais e profissionais. Cada grupo de trabalho elabora apresentações para defender sua argumentação, enquanto os demais alunos realizam questionamentos, objeções e proposições de melhorias. O grupo de alunos decide quais elementos devem se transformar em proposições e quais devem ser retirados.

$\mathrm{Na}$ fase de proposições, o ator externo assiste às apresentações dos alunos e de forma interativa realiza questionamentos e objeções às recomendações dos alunos. Por meio de um debate construtivo, mediado pelo professor-facilitador, as objeções são aceitas ou transpostas por meio de argumentação teórica e/ou criativa.

O grupo define as prioridades que cada recomendação aceita deve ser implementada pelo ator externo. $\mathrm{O}$ grupo acorda com o ator externo o próximo encontro, com tempo hábil para que um conjunto significativo de ações de intervenção possam ser implementadas e que possa ser dado um feedback aos alunos sobre os resultados e obstáculos que as ações de intervenção se defrontam.

O ciclo retorna a fase de debates e reflexões até a estabilização das recomendações.

O encerramento do caso se dá quando a carga horária do projeto se encerra, quando os alunos entendem que não há mais oportunidades de aprendizado, quando o professor-facilitador entende que o problema não é relacionado com conhecimentos de áreas de conhecimento da Administração ou quando o ator externo entende que o problema foi endereçado a contento. Lições aprendidas são elaboradas pelo grupo de alunos.

A seguir, dois casos são detalhados para ilustrar a operacionalização da metodologia exposta.

\section{CASOS ESTUDADOS}

A seguir estão descritos os resultados dos casos estudados.

\subsection{Caso da startup Aquarela}


O projeto-piloto foi realizado no primeiro semestre de 2015, onde houve participação voluntária de 13 alunos e da empresa chamada Aquarela, especializada em soluções em Big Data e incubada no MIDI Tecnológico.

Durante a rotulação do problema, os alunos efetuaram entrevistas com um dos empresários, realizando perguntas abrangentes para compreender a empresa, o segmento em que eles atuam, seus produtos e, principalmente, o que os levou a procurar ajuda no projeto.

O problema diagnosticado foi a falta de um processo para selecionar oportunidades de mercado e melhorar o argumento de vendas para um nicho selecionado. A empresa até então se valia de uma estratégia oportunista, gerando muitas possibilidades de ação comercial, porém sem um foco claro. Dessa forma, cada nova oportunidade de negócio era avaliada de forma pontual, sem um processo decisório consistente.

Alguns estudantes questionavam algumas questões tecnológicas e se a empresa deveria ter somente um produto. Para solucionar tais questões, as dúvidas foram enumeradas e levadas à empresa por uma comissão dos alunos designada a realizar uma visita técnica e uma análise documental.

Após essa investigação complementar, a comissão relatou ao grupo que não faria sentido estudantes de administração entrar em méritos computacionais. Os sócios concordaram com a visão dos alunos em possuir somente um produto no mercado, uma vez que uma startup não tem recursos disponíveis para abrir vários projetos simultâneos e isso estenderia ainda mais o tempo para a sustentabilidade financeira da empresa. Os empresários afirmaram que existiam oportunidades, mas que não conseguiam priorizá-las, gerando uma dificuldade em construir e comunicar uma proposta de valor para o segmento-alvo.

Após o rotular o problema, foi definido uma agenda de encontros, seguindo uma restrição de prazo de seis semanas imposta pelo professor-facilitador. Com essa ressalva, os alunos definiram um sistema de planejamento e monitoramento por iterações onde as datas mais próximas tinham entregáveis mais definidos e as finais ainda estavam incertas.

Com o plano de trabalho estabelecido, sucedeu-se uma discussão sobre quais áreas de conhecimento e suas respectivas técnicas seriam úteis para endereçar às questões da startup. Sendo elas:

- Marketing: Matriz BCG, Matriz SWOT, Funil de Vendas e CRM

- Inovação: Stage-Gate, Funil da inovação e Lean Startup

- Estratégia: Canvas Business Model, Value Proposition

- $\quad$ Avaliação de Desempenho: metodologia multicritério de apoio à decisão.

Para cada uma das técnicas-candidatas um grupo foi formado com o propósito de estudá-la e realizar uma apresentação aos outros colegas de forma a nivelar o conhecimento entre os alunos.

Antes da apresentação de cada técnica, o professor-facilitador instigou aos alunos a criar perguntas que poderiam ser respondidas pela execução da técnica. Após uma série de debates e argumentações, as perguntas norteadoras foram definidas como: “Eles sabem qual é o segmento deles? Eles sabem qual é o processo de vendas? Eles têm um produto maduro? Eles sabem como fazer a validação do produto?"

Das técnicas dispostas, a que os alunos entenderam como mais adequada foi o Lean Startup - LS (RIES, 2011). Onde o principal argumento utilizado pelos alunos foi a necessidade de um processo em que a empresa descobrisse por si só quais os segmentos com potencial e testá-los rapidamente para perceber se eram atendidos pela proposição de valor do produto da empresa. Os alunos reconheceram que, caso indicassem um segmento mesmo com argumentos adequados, essa sugestão teria resistência dos empresários por ser uma solução externa.

A partir do LS (RIES, 2011), entendeu-se que o processo de desenvolvimento de produto e a gestão comercial deveriam ser integrados, permitindo rápidas iterações de aprendizagem e que isso requereria critérios claros de decisão para avaliar os resultados. Assim, uma metodologia multicritério de apoio à decisão foi adotada como complemento ao método LS para criar tais critérios e decidir quais segmentos priorizar ou pivotar. Tal modelo de decisão deveria ser construído à luz dos valores e preferências dos gestores da startup, respeitando as singularidades de seus contextos.

Além dessas duas técnicas, entendeu-se que um só canvas para toda a empresa seria inócuo e, portanto, deveria ser criado um canvas para cada segmento de mercado pretendido.

Com esse plano de ação, o professor-facilitador solicitou aos alunos que definissem um fluxo visual do modelo de gestão proposto. Após discussões e de várias versões do desenho, a Figura 2 representa o resumo pictórico da proposta. 
Figura 2 - Resumo pictórico do modelo de gestão proposto pelo projeto-piloto

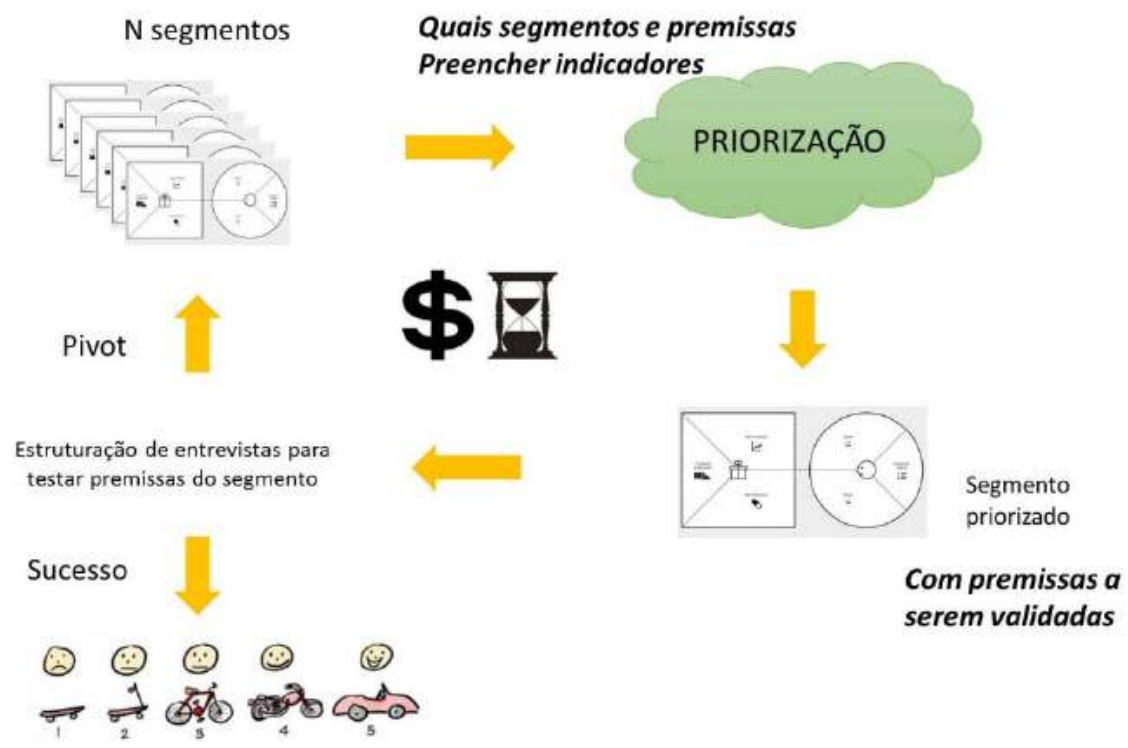

Fonte: Elaborado pelos autores (2016).

O fluxo proposto se iniciaria pela identificação e análise da proposição de valor do produto para cada segmento a ser trabalhado pela empresa. Perpassado pela identificação das "dores e ganhos" que cada segmento supostamente teria e quais as funcionalidades de produto e serviço que a empresa deveria ter para atender tais necessidades.

Os alunos enfatizaram que os empresários acreditavam que uma pesquisa de mercado tornaria o processo comercial lento e de alto custo. Assim, as proposições de valor são premissas, ou seja, verdades assumidas pelos empresários para sustentar ações gerenciais.

Apesar das premissas serem um instrumento gerencial válido para contextos incertos e dinâmicos, a startup não possuía um mecanismo para testar as premissas sistematicamente. Sem tal monitoramento, muitas vezes os empresários reportaram um investimento de tempo e orçamento em ações comerciais oportunistas que não culminavam em um fechamento.

A proposta dos alunos então, seria uma melhora no processo que, ao invés de ações comerciais reativas, os empreendedores deveriam priorizar os segmentos e agir de forma proativa a dissipar, da forma mais breve possível, as premissas que sustentam tal segmento como prioritário.

A próxima pergunta norteadora definida pelos alunos foi: Quais são os critérios que devem ser levados em conta para priorizar um dado segmento?

Em princípio, os alunos pesquisaram em artigos se existiria na literatura algum modelo pronto e encontraram algumas dicas na obra de Maurya (2012), que indicaria cinco critérios básicos usados nas escalas de likert: (i) nível da "dor" do cliente; (ii) facilidade de entrar neste segmento; (iii) margem de lucratividade; (iv) tamanho do mercado; (v) viabilidade técnica.

Alguns alunos ficaram relutantes na adoção de um modelo da literatura, sugerindo que esses critérios viessem dos próprios empresários. Em adição, pela sua ambiguidade, a escala de likert também teve resistência pelo grupo, pois era a prerrogativa do processo proposto que este fosse composto de argumentos claros para priorização de segmentos.

Porém, a restrição de tempo do projeto fez com que os alunos adotassem os critérios do modelo como um norte e determinassem os encontros restantes para legitimá-los junto aos empresários, que teriam palavra final sobre os mesmos além de proporem escalas de mensuração mais claras.

Apenas o critério "Nível da 'Dor' do Segmento" foi aceito sem alterações. O critério "Facilidade de entrar neste segmento" foi desdobrado nos itens "Networking no segmento", "Tempo para Fechar Ciclo de Faturamento" e "Ponto que está no Funil de Vendas". O critério de "viabilidade técnica" foi transformado em "Maturidade Tecnológica do Segmento". Já os critérios de "margem de lucratividade do segmento" e "tamanho do mercado" foram declinados, com o argumento de que o produto não seria de massa. 
Após a definição dos mesmos, os gestores foram instigados pelos alunos a criarem uma ordem de preferência para cada um deles e que deixassem claro o que seria um segmento atrativo em cada critério. A Figura 3 explicita uma escala construída pelos alunos em conjunto com os empresários da startup.

Figura 3 - Indicador e escala para o critério Tempo para fechar ciclo de faturamento

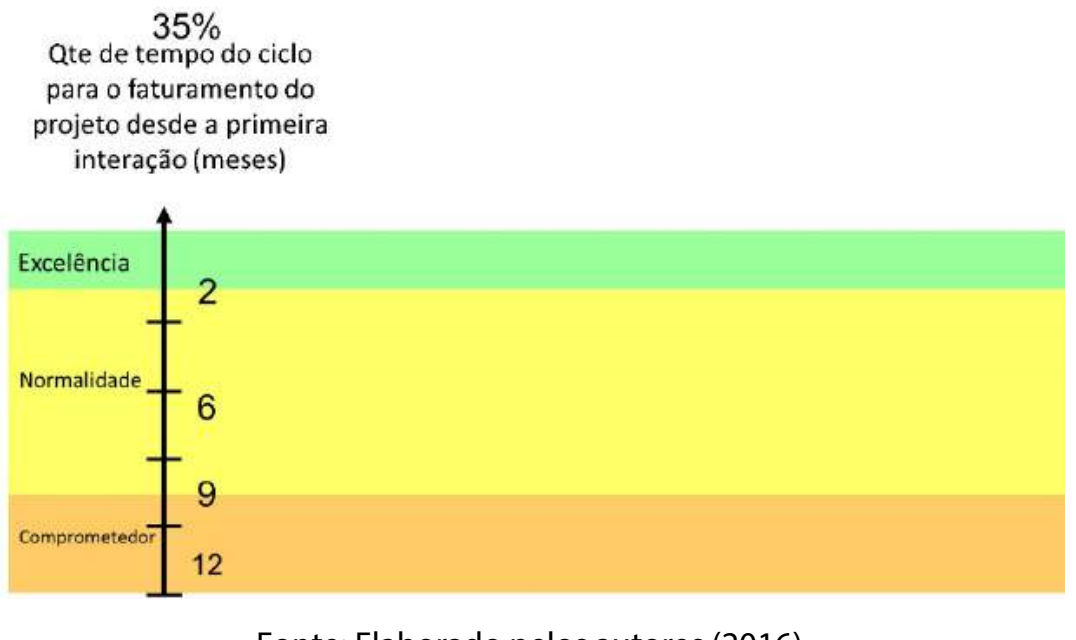

Fonte: Elaborado pelos autores (2016).

A partir da definição de todas as escalas do modelo, pôde-se avaliar os segmentos de forma qualitativa. Sendo assim, os gestores propuseram trabalhar com o de supermercados, pois já teriam pago um evento desse segmento. A premissa era de que o nível da dor desse segmento era alto, uma vez que a startup supunha que estes poderiam utilizar seu produto como forma de otimizar a fidelização de seus clientes. O nível de maturidade tecnológica estaria em na normalidade, pois tal segmento não faria uso de sistemas sofisticados de informações. Os demais critérios ficavam em níveis comprometedores.

Mesmo que não atraente, os alunos aproveitaram a oportunidade para testar se o modelo proposto era válido. Assim, um conjunto de perguntas foram sugeridas para entrevistar executivos do segmento de supermercados. $\mathrm{O}$ Quadro 1 explicita tais perguntas.

Quadro 1 - Premissas vs. perguntas para serem realizadas aos gerentes de supermercado.

\begin{tabular}{|l|l|}
\hline \multicolumn{1}{|c|}{ Premissa } & \multicolumn{1}{c|}{ Pergunta } \\
\hline $\begin{array}{l}\text { O supermercado tem } \\
\text { necessidade de fidelização }\end{array}$ & $\begin{array}{l}\text { Você tem necessidade do número de clientes fidelizados? Por que foi implementado o } \\
\text { programa de fidelização? Como é o uso do programa? Tem respostas conclusivas? Qual } \\
\text { o objetivo com o programa de fidelização? }\end{array}$ \\
\hline $\begin{array}{l}\text { O supermercado grande tem } \\
\text { fidelização de clientes }\end{array}$ & $\begin{array}{l}\text { Vocês têm algum programa de fidelização de clientes? Ex: Programa de pontos, cartão } \\
\text { da rede etc. }\end{array}$ \\
\hline O supermercado grande usa Bl & Existe análise de dados? Quais áreas? Como é realizada a análise de dados? \\
\hline $\begin{array}{l}\text { O supermercado não sabe o } \\
\text { público-alvo para cada filial }\end{array}$ & $\begin{array}{l}\text { Quantas filiais? Cada filial tem um público específico? Como você sabe que os produtos } \\
\text { das gôndolas estão condizentes com o público-alvo de cada filial? Gostaria de descobrir } \\
\text { o público-alvo em cada filial? }\end{array}$ \\
\hline $\begin{array}{l}\text { O supermercado é resistente a } \\
\text { adoção de inovações } \\
\text { tecnológicas }\end{array}$ & $\begin{array}{l}\text { Quais inovaçães tecnológicas (código de barra, controle de estoque, etiqueta eletrônica } \\
\text { etc.) que vocês realizaram no supermercado? Como foi o processo de adoção? }\end{array}$ \\
\hline
\end{tabular}

Fonte: Elaborado pelos autores (2016). 
Após a realização das entrevistas, observou-se que o nível da dor desse segmento era baixo, visto que os supermercados já tinham uma sólida ação de fidelização de clientes e o nível de maturidade tecnológica era alto, com uso intensivo de sistemas de business intelligence. Após apresentarem os resultados aos empresários, estes concordaram que este setor não seria mais atraente. Isto serviu para que os gestores percebessem como um processo sistemático de avaliação de oportunidades e rápida averiguação, poderia melhorar o seu processo comercial.

Para que seja feita a avaliação dos segmentos, a metodologia multicritério preconiza que os níveis de desempenho das escalas sejam comparados, de forma a definir as taxas de compensação, vulgarmente chamadas pelos alunos como "pesos" dos critérios. Como o termo "peso" não está cientificamente correto, o professor-facilitador apresentou os conceitos, mas os deixou livre para arbitrarem um termo que faria mais sentido para eles e para os gestores da startup estudada.

Após a definição dos "pesos" de cada critério, as escalas de mensuração foram transformadas em escalas numéricas, onde o nível superior da normalidade foi atribuído 100 pontos e o inferior da normalidade 0 pontos. Os demais níveis das escalas foram definidos de maneira linear, uma vez que não existia tempo hábil para definição de escalas usando técnicas mais refinadas.

Nesse ponto do processo, o grupo, juntamente com os gestores, elencou três potenciais segmentos da startup e criaram premissas de desempenho para cada um dos critérios. O modelo foi convertido para um banco de dados para emissão de relatórios gerenciais. Na Figura 4 está apresentado um relatório com três segmentos: Telecomunicações, Pagamentos eletrônicos e Tribunais.

Dentro da metodologia Lean Startup (RIES, 2011), essa ordenação de segmentos é dinâmica, ou seja, conforme o aprendizado dos testes de premissas, os segmentos podem variar sua ordenação com informações fidedignas obtidas a partir da interação com o mercado. Também podem surgir novos segmentos de atuação e esses devem ser avaliados de forma disciplinada, evitando assim uma estratégia oportunista, que apesar de parecer atraente no curto prazo, tornase comprometedora em termos estratégicos

Figura 4 - Relatório com três segmentos priorizados para a empresa estudada

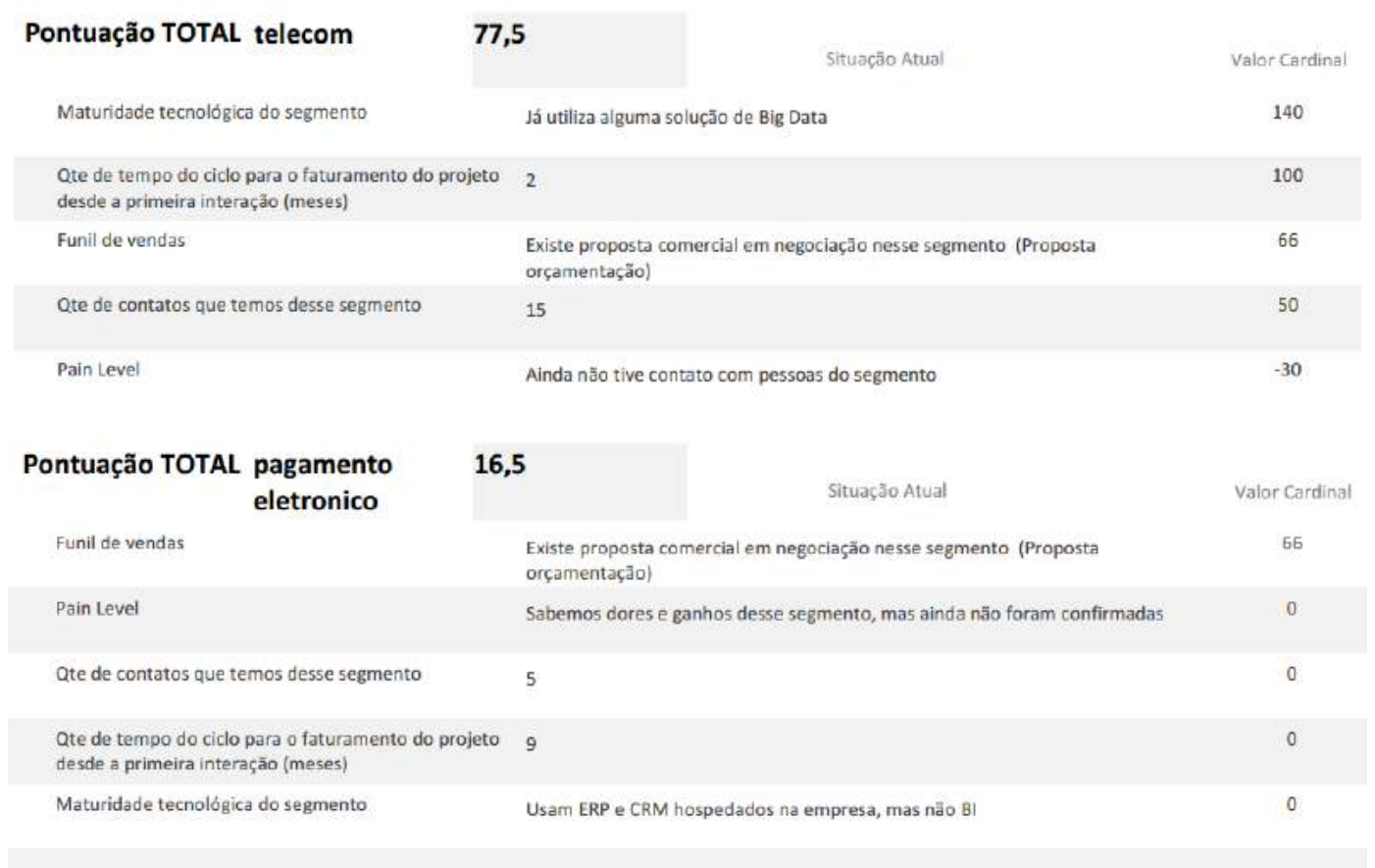




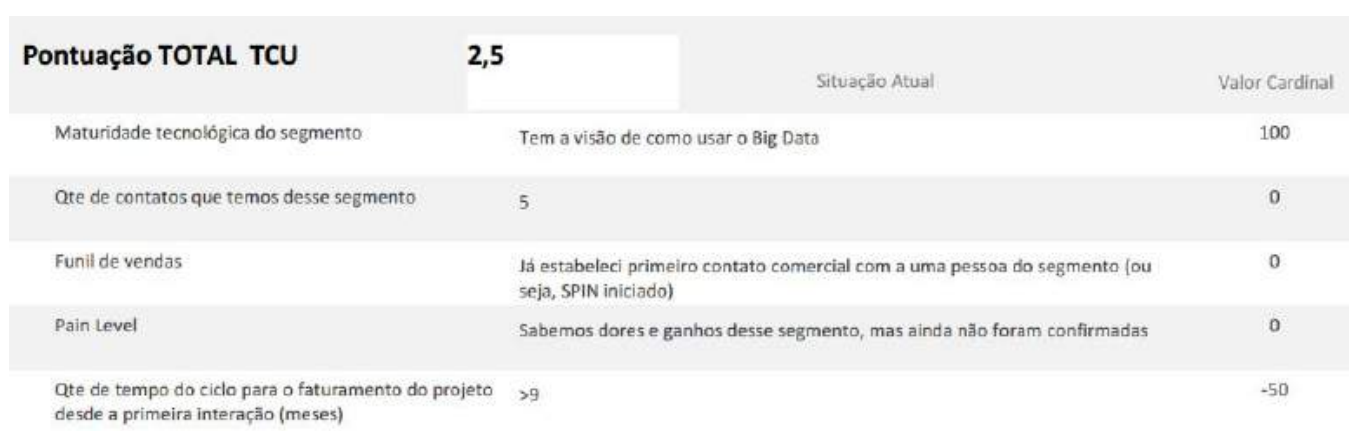

Fonte: Elaborado pelos autores (2016).

Além da entrega do modelo em banco de dados automatizado, o grupo também entregou um fluxo de processos também baseado no LS (RIES, 2011), para explicar cada atividade do modelo de gestão proposto. Como pode ser verificado, na Figura 5.

Figura 5 - Fluxo de processos proposto

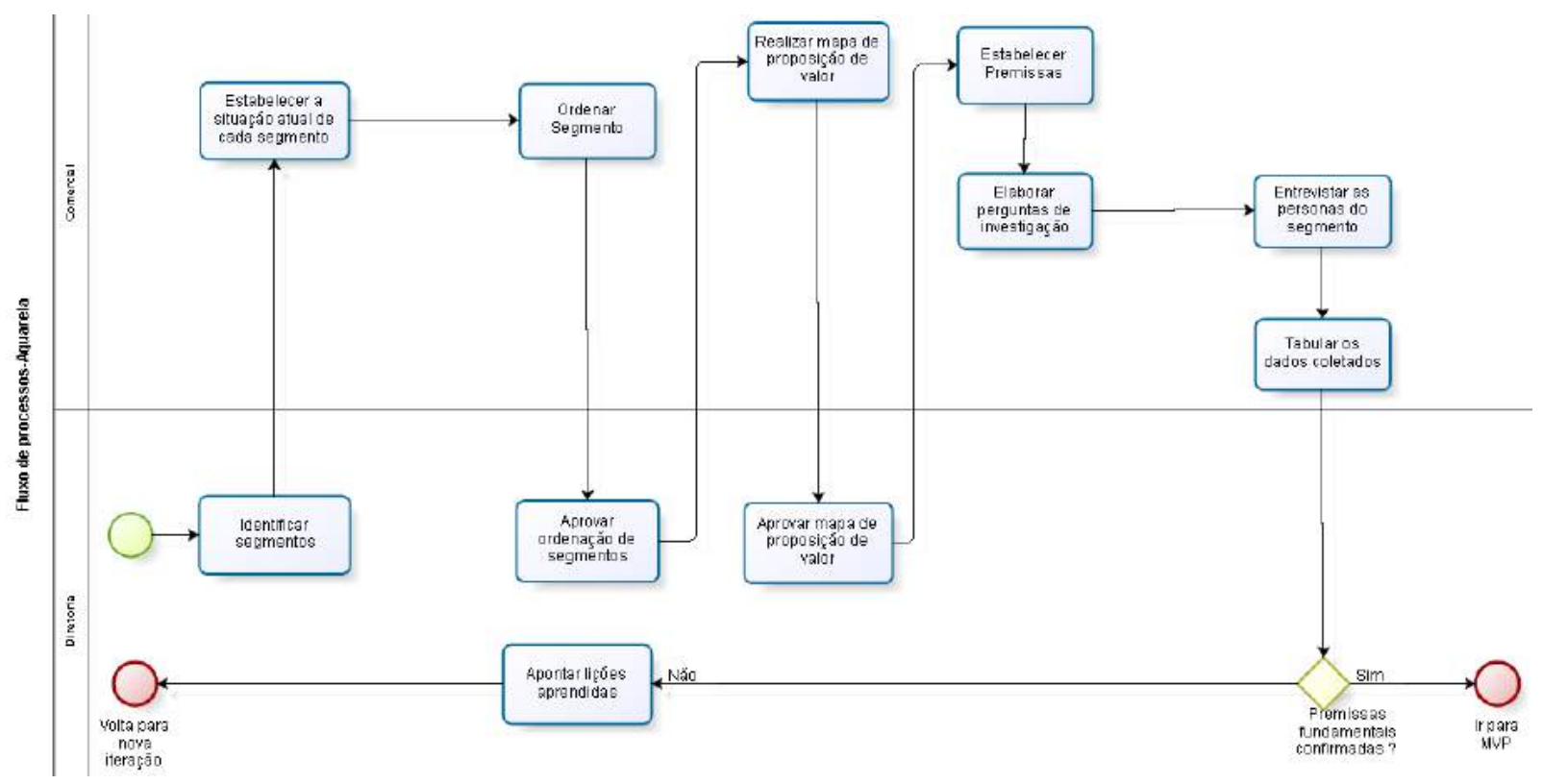

Fonte: Elaborado pelos Autores (2016).

Depois das entregas finais do projeto, o professor-facilitador solicitou aos empresários um feedback sobre o trabalho realizado e foi informado pelo gestor que "nenhuma consultoria havia apresentado algo similar", dado que as consultorias possuem uma metodologia genérica.

\subsection{Caso da startup Pensys}

O caso Pensys foi realizado no segundo semestre de 2015 com 16 alunos participantes, dentro da mesma metodologia de aprendizagem proposta por esse artigo. No primeiro encontro, o objetivo foi conhecer mais profundamente a organização, assim como seus gestores e elencar pontos para a identificação do problema da organização.

O que define o "carro chefe" dessa startup é robotização. O diferencial da empresa citado pelos gestores é que eles unem a parte física dos equipamentos (hardware) com a parte de programação (software), enquanto a grande maioria das empresas do segmento se atentam apenas a esta última. O negócio da empresa consiste em licenciar produtos, viabilizando que terceiros que possam comercializá-los e até manufaturá-los. 
Um dos problemas apontados pelos sócios é que, com mais de oito projetos em execução, algumas vezes faltam dados sobre que prioridades que a empresa deve estabelecer. Eles encontram dificuldades em definir em qual momento devem diversificar ou quando devem focar em um determinado mercado. Sendo assim, eles sentem a ausência de critérios claros para a escolha de quais projetos devem ser priorizados.

Uma vez determinado o objetivo norteador do projeto, os alunos foram instigados a refletir sobre áreas de conhecimento e técnicas que seriam úteis para o início da estruturação das recomendações. O grupo selecionou as seguintes áreas

Marketing: as técnicas de Matriz BCG e Matriz McKinsey;

Gestão de Produção: as técnicas de manufatura puxada, como: Ishikawa, Kanban e gestão logística;

Gestão de Processos: a matriz de apoio à decisão;

Estratégia a matriz SWOT.

Os alunos também concordaram que a área de inovação seria importante, mas nesse primeiro momento, nenhuma técnica em específico foi proposta pelos alunos.

Na sequência, o grupo se organizou de forma de criar comissões para estudar as técnicas candidatas de acordo com a seguinte pergunta norteadora: Quais os fatores que levariam essa startup ao melhor projeto?

No encontro seguinte, todas as comissões expuseram seus aprendizados sobre seus respectivos temas e técnicas. Havia um consenso de que a startup deveria olhar para suas próprias competências e interesses, ao invés de privilegiar o que está sendo demandado pelo mercado. Essa premissa de trabalho foi baseada em afirmações dos empreendedores, como:

\footnotetext{
"... quando um cliente já demandou uma solução em específico, o grau de inovação é baixo...o que precisamos estar a atento são nas necessidades dos usuários e não no que eles nos pedem..."

"... temos que enxergar alguns pontos de motivação da própria equipe de desenvolvimento do projeto para acelerar o andamento ..."

"... queremos fazer produtos com a nossa cara, trabalhar com amor à tecnologia"
}

Assim, vários fatores de preocupação explicitados pelos gestores da startup foram colocados em um diagrama de Ishikawa. Todavia, o formato preconcebido de critérios dessa técnica deixaram o grupo reflexivo, pois haviam critérios que não se enquadravam bem, como custo, mão de obra etc. Assim, os alunos foram questionados pelo professorfacilitador sobre o porquê da criação do diagrama. O grupo discutiu e chegou a um consenso de que ele serviria para analisar as causas que poderiam levar à boas escolhas de projetos. O professor-facilitador, então, os instigou a usarem essa afirmação para criarem seus próprios critérios a partir das entrevistas com os gestores.

Após várias versões de diagramas no quadro branco, os alunos acordaram numa versão final. Esta é apresentada na Figura 6. 


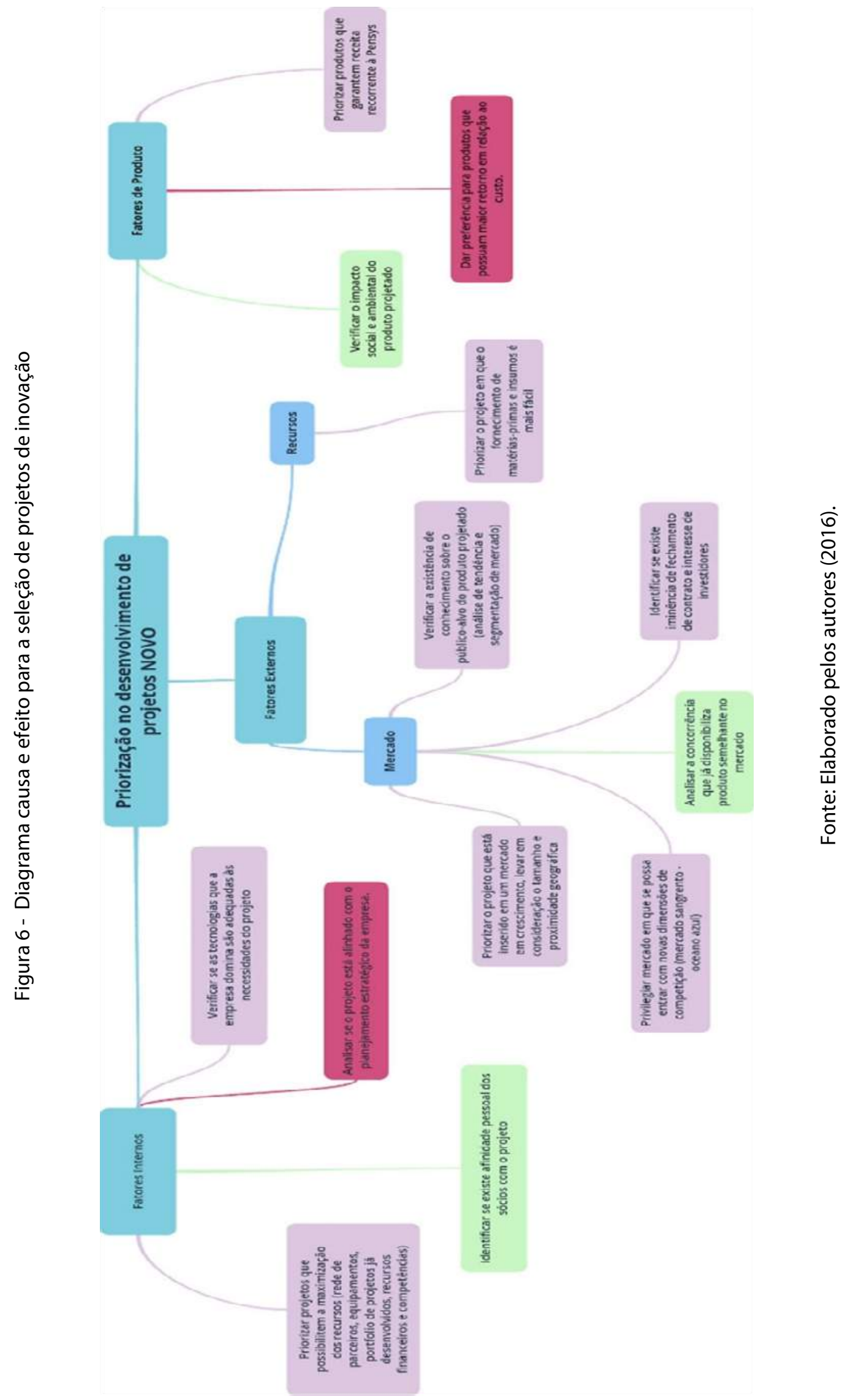


Com o diagrama realizado, o professor apresentou os conceitos teóricos dos mapas cognitivos (EDEN; ACKERMANN; CROPPER, 1992). Desse exercício, surgiram três clusters de decisão: Fatores Externos (FE), Fatores Internos (FI) e Fatores de Produto (FP).

Todavia, o próximo desafio do grupo era legitimar essa estruturação de ideias, uma vez que os elementos foram extraídos da entrevista com apenas um dos quatro acionistas da startup. Essa preocupação adveio da seguinte afirmação do empresário: "Um de nossos desafios é harmonizar o interesse dos sócios, ter a química entre as diferentes áreas de tecnologia da empresa."

O professor-facilitador nesse momento colocava o desafio aos alunos para que tentassem obter uma solução harmoniosa. Dessa forma, foram realizados encontros individuais com cada um dos quatro sócios para que estes tecessem considerações sobre o diagrama. O grupo decidiu evitar a exclusão do critério caso este fosse interessante para ao menos um acionista.

Para solucionar os impasses, os alunos decidiram criar os "pesos" dos critérios, que iriam ser estabelecidos para garantir que o maior número de interesses dos acionistas fosse atendido pelo modelo de decisão. Os critérios finais são apresentados pela Quadro 2.

Quadro 2 - Critérios estabelecidos pelo grupo de acionistas para avaliação de projetos

\begin{tabular}{|l|l|}
\hline FE 01 & Crescimento de mercado em relação ao ano anterior \\
\hline FE 02 & Grau de conhecimento do público-alvo \\
\hline FE 03 & Grau de iminência de fechamento de contrato \\
\hline FE 04 & Nível da concorrência \\
\hline FE 05 & Quantidade de dimensões competitivas \\
\hline FE 06 & Fornecimento de Insumos \\
\hline FI 01 & Domínio da Tecnologia pela empresa \\
\hline FI 02 & Grau de alinhamento estratégico \\
\hline FI 03 & Grau de afinidade pessoal com o projeto \\
\hline FI 04 & Recursos do projeto (parceiros, equipamentos, pessoas, espaço etc). \\
\hline FP 01 & Grau de impacto das políticas ou benefícios associados à RSA (pessoas impactadas) \\
\hline FP 01 & ROl em 2 anos após lançamento \\
\hline FP 01 & Modelo de rents do produto \\
\hline
\end{tabular}

Fonte: Elaborado pelos autores (2016).

A cada encontro com um dos empresários, questionava-se a respeito de que critério ele entendia como o mais importante e, coletivamente, foram construídas escalas de mensuração para ordenar os projetos da empresa. É importante destacar que dos treze critérios propostos, apenas dois critérios usavam escalas numéricas: FP02 - ROI em 2 anos após lançamento e FP01 Grau de impacto das políticas ou benefícios associados à Responsabilidade Socioambiental.

A princípio, o FP01 seria avaliado pelo número de pessoas impactadas, porém a coleta desse dado seria extremamente difícil. O grupo chegou a propor a exclusão desse indicador, mas os acionistas não aceitaram, pois esta era uma questão de relevância para todos os sócios. Foi proposta, então, a utilização da escala de likert para atender a restrição de tempo do projeto, apesar da ambiguidade de sua mensuração.

Na Figura 7, está explicitado uma escala qualitativa para mensurar um critério do modelo.

Figura 7 - Escala do indicador que avalia modelo comercial de um produto da startup

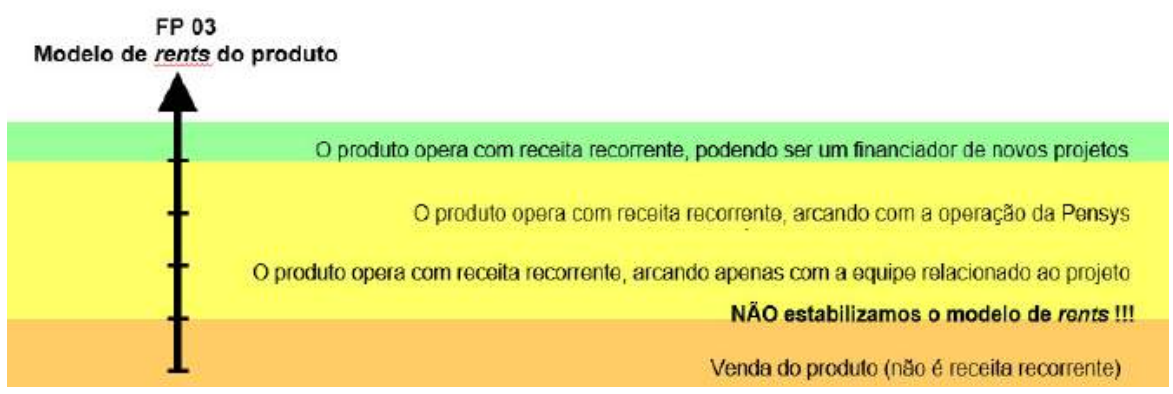

Fonte: Elaborado pelos autores (2016). 
Nesse ponto do projeto, o grupo consumiu mais que a metade dos encontros na estruturação, estabilização e legitimação dos critérios de priorização de produtos. O professor-facilitador os orientou a definir quais seriam as recomendações devido à restrição de tempo. O grupo decidiu que as prioridades seriam a finalização do modelo de decisão e selecionar como ele seria utilizado.

Para a finalização do modelo, optou-se pela geração de uma pontuação direta para cada escala, ou seja, o nível superior da normalidade foi atribuído 100 pontos e ao nível inferior da normalidade 0 pontos. Os demais níveis das escalas foram definidos de forma arbitrária por um dos sócios da empresa.

Os "pesos" foram definidos da seguinte forma: aos critérios que foram ditos como fundamentais por todos os acionistas, foram atribuídos $15 \%$ de "peso". Para critérios que foram citados por dois acionistas como fundamentais, tiveram seu "peso" definido em $7 \%$. Os demais critérios tiveram peso de $2 \%$.

Apesar da simplicidade dessa definição, o grupo acordou que a principal contribuição está no processo de avaliação, não na geração de um modelo definitivo. Essa prerrogativa foi aceita pelos acionistas que tinham receio da adoção de um modelo estático, que não atendesse as condições dinâmicas típicas de uma startup. Essa simplificação na conversão das escalas qualitativas em quantitativas foram mitigadas pela disponibilização de um banco de dados que pudesse ser customizado pelos próprios empresários na sua execução.

A última etapa do projeto foi buscar responder à pergunta: "Como utilizar esse modelo de decisão? ". Assim, o modelo de inovação stage-gate foi identificado como uma proposição interessante, dado que preconiza o uso de indicadores para a decisão de "go or kill" de projetos (COOPER, 2008).

A contribuição dos alunos para o modelo atual seria priorizar os projetos, baseados no desempenho suposto de cada produto em cada critério de avaliação, ou seja, a cada gate uma nova avaliação seria realizada pelos acionistas, de forma a questionar continuamente se as prioridades de produtos continuam válidas ou se é preciso analisar mudanças.

Dessa forma, o processo de desenvolvimento seria baseado em uma busca contínua de dissipação de incertezas por meio de testes de premissas que usam iterações evolutivas de produto, chamadas pela abordagem $L S$, como MVP ("minimum viable product"). A Figura 8 ilustra o processo proposto.

Figura 8 - Processo proposto para avaliar projetos

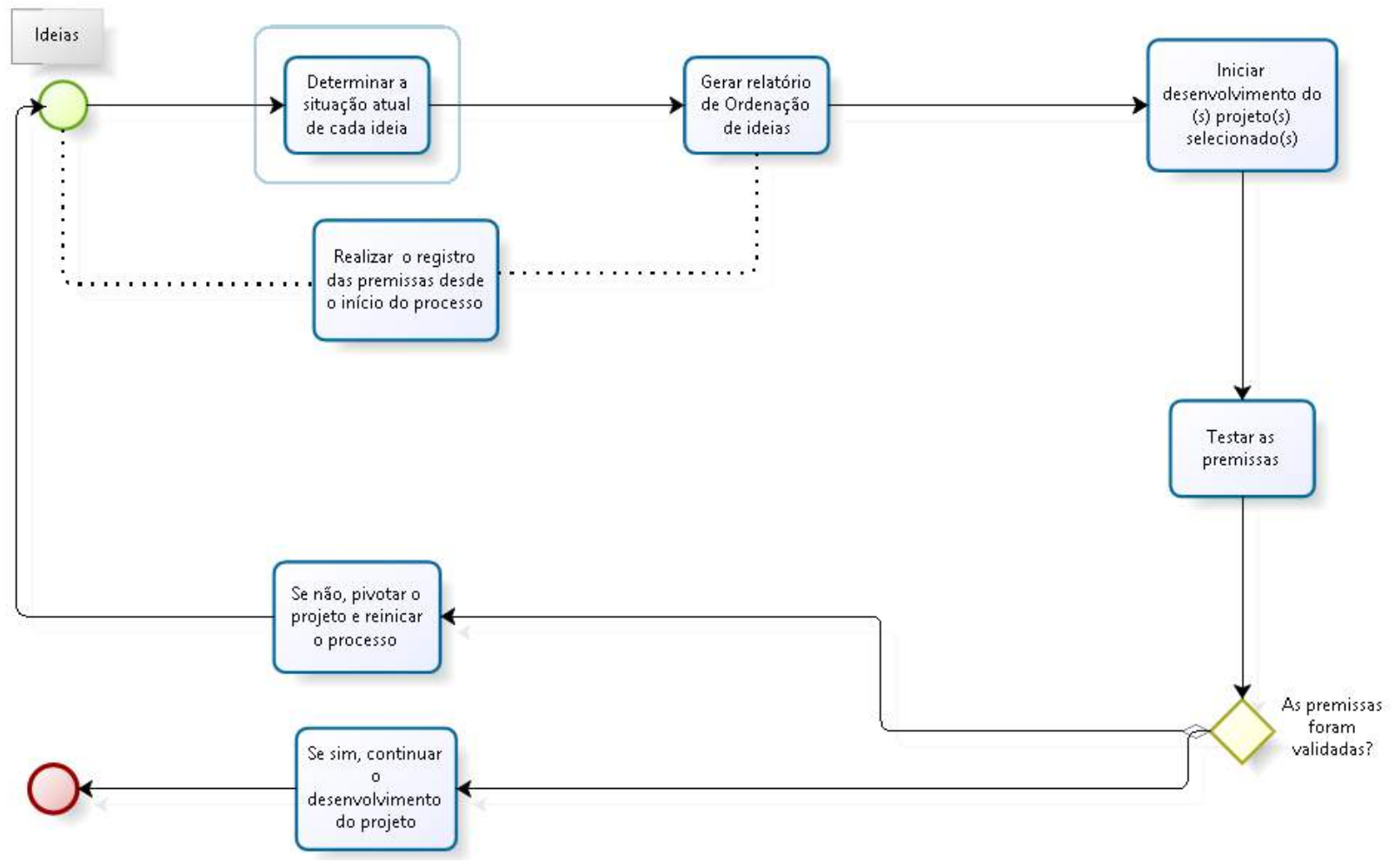

Fonte: Elaborado pelos autores (2016). 


\subsection{Discussão dos casos}

Apesar do Lean Startup (RIES, 2011) ter sido utilizado como fonte metodológica em ambos os casos, as razões da sua adoção e sua operacionalização foram diferentes. O grupo constituído para resolver o problema foi completamente distinto para cada caso, exceto na condição do professor-facilitador que procurou manter a isenção e respeitar as decisões do grupo de forma colegiada. O papel do professor-facilitador foi apenas apontar riscos e apresentar questionamentos que pudessem ampliar o entendimento dos participantes.

Um elemento que explica essa diferença de operacionalização do $L S(R I E S, 2011)$ é constituído pelos aspectos singulares das duas startups. Os decisores de ambas têm visões de mundo, valores e preferências distintas entre si e procuram alcançar seus objetivos da forma que entendem e se relacionam com o mundo.

Essa divergência, sob a ótica realista normativista, poderia suscitar que um, ou os dois casos, estavam "errados" e teriam soluções ótimas a serem aceitas. Porém, conforme informações dos próprios empreendedores participantes, soluções universais exógenas ao contexto sofrem grandes resistências para sua implantação e tendem a cair no desuso.

Outra observação que se pode obter dos dois casos é o uso da metodologia multicritério de apoio à decisão, pois auxilia a construir um entendimento sobre o que é relevante em um dado contexto na perspectiva dos decisores.

A respeito dessa integração de apoio à decisão com ambientes dinâmicos típicos de startups, pode-se observar que o principal benefício não se dá efetivamente pelo seu resultado final em si, ou seja, pelos critérios, indicadores e as questões matemáticas associadas a essas metodologias de avaliação. Nos dois estudos de caso, observou-se maior interesse dos participantes na construção dos critérios e escalas do que nas questões matemáticas e mecanicistas dos modelos.

Observa-se que os gestores e alunos participantes nesses dois projetos estão mais interessados em entender as causas que levariam a uma boa decisão, do que na ordenação das alternativas em si.

Essa pesquisa abre a oportunidade para investigar se tais refinamentos matemáticos são úteis em ambientes dinâmicos, como nos processos de inovação e gestão de empresas nascentes.

Outro ponto importante da integração entre gestão de startups e o apoio à decisão é que: o primeiro caso relata preliminarmente a preocupação do processo de gestão e posteriormente a avaliação de desempenho, já no segundo, percebe-se que o processo de entendimento dos critérios consumiu boa parte do tempo e só depois houve a preocupação dos participantes em como esse processo seria adotado pela startup.

De forma que a avaliação de desempenho surge como elemento importante tanto na perspectiva top-down como na estratégia bottom-up, sendo um vínculo entre as questões estratégicas que operacionalizam os valores e preferências do decisor até as questões de escolhas segmentos de mercado e projetos.

A metodologia de apoio à decisão também se mostrou útil no momento do teste de premissas preconizados pela abordagem $L S$. Nos dois casos apresentados, tais premissas foram baseadas no nível de desempenho suposto pelos gestores em cada critério avaliado. Assim, o segmento ou o projeto priorizado não garante ser o mais adequado, muito menos uma solução ótima, mas aquele que, segundo a percepção de gestores, tem o maior alinhamento com que eles desejam para a empresa. A confirmação, ou não, do estado atual das alternativas na escala, será avaliada por meio dos testes dessas premissas, que devem fazer parte do processo de desenvolvimento de produto.

Ao contrário de organizações já estruturadas, a coleta de dados em startups para entender a situação atual de cada segmento ou projeto em execução pode se tornar bastante onerosa e demorada, como é exemplificado nos indicadores de responsabilidade socioambiental, ou de retorno do investimento, que exigiam um plano de negócios.

Dentro de uma postura racionalista essa decisão gerencial se apresentaria como evidência de um erro gerencial. Porém, ao aceitar o conhecimento limitado, esse risco pode ser assumido pelos decisores, desde que as premissas se tornem elementos formais que as organizações devem mitigar com a maior celeridade.

Ou seja, um dado segmento só está sendo priorizado porque aquelas premissas foram assumidas. A partir do momento em que a situação atual da coleta de dados for inferior à sua posição na escala dos indicadores, uma nova avaliação deve ser realizada para saber se aquele segmento ou projeto continua sendo atrativo para a organização.

Com essa abordagem dinâmica e inovadora, pode-se entender a avaliação de desempenho como instrumento de apoio à decisão para contextos de rápidas mudanças, inovação e descoberta de mercados. Tal dinamismo é explicitado nos casos, onde os segmentos e produtos podem ter sua prioridade alterada conforme novos elementos de campo sejam obtidos, contextos competitivos sejam alterados, novas ideias sejam propostas, ou se novas proposições de valor de usuários forem identificadas. 
A respeito das abordagens decisão, os dois casos também trouxeram algumas questões para reflexão. A primeira é: como o tempo e a pressão das restrições para resolver o problema podem afetar a adoção, ou não, de uma abordagem. No primeiro caso, como o foco preliminar foi mais na metodologia que no modelo de decisão, sobrou pouco tempo para refletir sobre os critérios, surgindo então a alternativa mais rápida de obtê-los a partir da literatura. Porém, os decisores não reconheceram nesses critérios universais os seus valores e preferências e, sendo assim, eles fizeram questão de alterar e propor novos critérios. Afirmações como "esse não é o DNA da nossa empresa" ou "será que essa porta será aberta com a nossa chave? " podem corroborar com a conclusão que a legitimação é vital para que o processo de gestão seja parte da cultura organizacional de uma startup.

É importante reconhecer que a literatura foi útil para construção de um entendimento e uma proposição inicial, dando proatividade ao processo de criação de indicadores e critérios. Pode-se aceitar, então, que a literatura, como elemento universal, acelerara a construção de entendimento, porém dificilmente será aceita em um dado contexto em específico.

Já no segundo caso, o modelo de decisão surgiu a partir da identificação das consequências de não conseguir acordar quais seriam os valores e preferências dos decisores. Apontando claramente uma filiação construtivista ao utilizar técnicas para ampliar o entendimento do problema pelos decisores e participantes.

\section{CONCLUSÃO}

Esse artigo relatou os resultados de dois casos que propuseram práticas de gestão inovadoras por meio de uma metodologia que visa (i) difundir práticas gerenciais inovadoras em empresas startups, (ii) estreitar a relação teoria e prática no ensino da Administração, sobretudo em ambiente dinâmicos, (iii) criar um ambiente propício ao desenvolvimento das competências dos alunos com um enfoque de aprendizagem pela ação, ao mesmo tempo que os empresários das empresas incubadas possam refletir sobre seus processos de gestão.

No tocante ao primeiro objetivo, os dois casos apresentados utilizam da abordagem Lean Startup (RIES, 2011) para resolver problemas de duas startups em momentos distintos e com facilitadores distintos. Os casos apresentam uma integração inovadora e de simples implementação, sobre como a abordagem LS (RIES, 2011) pode se beneficiar de uma integração com uma metodologia multicritério de apoio à decisão construtivista.

A respeito do segundo objetivo do artigo, o uso de um método de aprendizagem ativa faz com que os alunos tenham de aplicar um conjunto interdisciplinar de conhecimentos, como marketing, operações e gestão de inovação para conseguir gerar recomendações. Por algumas vezes, os alunos se surpreenderam pelo fato dos gestores das startups não terem um modelo de gestão para avaliar produtos e mercado, dado que a literatura apresentada a eles em aulas expositivas apresenta um quadro do mundo corporativo bem mais avançado e maduro do que os que eles tiveram contato nesses dois casos.

Por fim, o terceiro objetivo foi atingido uma vez que todas as proposições de melhorias foram legitimadas pelos gestores das startups. Por algumas vezes, os gestores das startups concordam que evidenciaram exacerbamento das questões tecnológicas em detrimento às questões estratégicas e gerenciais. Obviamente, por ser tratar de empresas de base tecnológica, esta, fica sendo um elemento central nesse tipo de organização.

Porém, existe uma importante oportunidade de pesquisa para entender como inserir em uma startup a cultura estratégica por meio de exercícios cognitivos que ao mesmo tempo: (i) ampliem o entendimento dos empresários a respeito do seu negócio, (ii) que façam sentido na sua estrutura de valores e preferências, aumentando assim as chances de sua adoção na empresa por amplos períodos de tempo e (iii) se insiram dentro do processo de desenvolvimento de produtos, de modo a manter o alinhamento com a tecnologia, não sendo a gestão vista como um elemento de dispêndio de tempo e recursos.

Dessa forma, apesar de pouco explorado na literatura científica, no ponto de vista prático, o construtivismo tem uma ampla aplicabilidade dentro do ambiente das startups, pois cria um contexto onde os decisores possam realmente discutir o que estão pensando e procurar entender as consequências de longo prazo das suas decisões, onde tal elemento se torna fundamental em uma empresa em estruturação. 


\section{REFERÊNCIAS}

ACHANGA, Pius et al. Critical success factors for lean implementation within SMEs. Journal of Manufacturing Technology Management, v. 17, n. 4, p. 460-471, 2006.

BANA E COSTA, C. A. Processo de Apoio à decisão: Problemáticas, Actores e Acções. ENE/UFSC. Florianópolis, 1995. COOPER, Robert G. Perspective: The stage-gate ${ }^{\circledR}$ idea-to-launch process-update, what's new, and nexgen systems. Journal of Product Innovation Management, v. 25, n. 3, p. 213-232, 2008.

DINGS $\varnothing Y R, T$. et al. A decade of agile methodologies: Towards explaining agile software development. Journal of Systems and Software, v. 85, n. 6, p. 1213-1221, 2012.

EDEN, Colin; ACKERMANN, Fran; CROPPER, Steve. The analysis of cause maps. Journal of management Studies, v. 29, n. 3, p. 309-324, 1992.

EDMONSTONE, John. The Action Learner's Toolkit. London:Gower Publishing Company Limited, 2003.

ENSSLIN, L.; MONTIBELLER NETO, G.; NORONHA, S. M. D. Apoio à decisão: metodologias para estruturação de problemas e avaliação multicritério de alternativas. Florianópolis: Insular, 2001.

GIL, Antonio Carlos. Como elaborar trabalhos de pesquisa. São Paulo: Atlas, 1991.

HALLGREN, Mattias; OLHAGER, Jan. Lean and agile manufacturing: external and internal drivers and performance outcomes. International Journal of Operations \& Production Management, v. 29, n. 10, p. 976-999, 2009.

HASIN, Sanjay; BURCHER, Peter. Lean viewed as a philosophy. Journal of manufacturing technology management, v. 17, n. 1, p. 56-72, 2006.

HUDSON, M.; SMART, A.; BOURNE, M. Theory and practice in SME performance measurement systems. International Journal of Operations \& Production Management, v. 21, n. 8, p. 1096-1115. 2001.

LACERDA, RTO; ENSSLIN, Leonardo; ROLIM ENSSLIN, Sandra. A performance measurement framework in portfolio management: A constructivist case. Management Decision, v. 49, n. 4, p. 648-668, 2011.

LORD, Thomas R. A comparison between traditional and constructivist teaching in college biology. Innovative Higher Education, v. 21, n. 3, p. 197-216, 1997.

MCCARTHY, J. Patrick; ANDERSON, Liam. Active learning techniques versus traditional teaching styles: two experiments from history and political science. Innovative Higher Education, v. 24, n. 4, p. 279-294, 2000.

MACVAUGH, Jason; NORTON, Mike. Introducing sustainability into business education contexts using active learning. International Journal of Sustainability in Higher Education, v. 13, n. 1, p. 72-87, 2012.

MAURYA, Ash. Running lean: iterate from plan A to a plan that works. Sebastopol: O'Reilly, 2012.

MARQUARDT, M. J. O poder da aprendizagem pela ação: como solucionar problemas e desenvolver líderes em tempo real. Rio de Janeiro: Senac Rio, 2005.

PEDLER, Mike. Action learning in practice. Burlington:Gower Publishing, Ltd., 2011.

PETTERSEN, Jostein. Defining lean production: some conceptual and practical issues. The TQM Journal, v. 21, n. 2, p. $127-142,2009$.

POWNER, Leanne C.; ALLENDOERFER, Michelle G. Evaluating hypotheses about active learning. International Studies Perspectives, v. 9, n. 1, p. 75-89, 2008. 
QUMER, Asif; HENDERSON-SELLERS, Brian. An evaluation of the degree of agility in six agile methods and its applicability for method engineering. Information and software technology, v. 50, n. 4, p. 280-295, 2008. RIES, Eric. The lean startup: How today's entrepreneurs use continuous innovation to create radically successful businesses. New York: Crown Books, 2011.

ROY, B. Decision science or decision-aid science? European Journal of Operational Research, v. 66, n. 2, p. 184-203, 1993.

TRKMAN, Peter. The critical success factors of business process management. International journal of information management, v. 30, n. 2, p. 125-134, 2010.

TRIVIÑOS, Augusto Nibaldo Silva. Introdução à pesquisa em ciências sociais: a pesquisa qualitativa em educação. $O$ positivismo; a fenomenologia; o marxismo. São Paulo: Atlas, 1987.

YIN, Robert K. Case study research: Design and methods. Thousand Oaks: Sage publications, 2013.

WYNN-WILLIAMS, Kate; WHITING, Rosalind H.; ADLER, Ralph W. The influence of business case studies on learning styles: An empirical investigation. Accounting Education: an international journal, v. 17, n. 2, p. 113-128, 2008. 